DOI 10.37882/2500-3682.2021.09.08

\title{
СОЦИАЛЬНО-ПСИХОЛОГИЧЕСКИЕ ДЕТЕРМИНАНТЫ НАБЛЮДАТЕЛЬНОСТИ ПРОФАЙЛЕРА ОТ ЛичнОстИ к ИМИдЖУ
}

\section{THE MODEL OF SOCIO-PSYCHOLOGICAL DETERMINANTS OF PROFILERS OBSERVATION ABILITY}

\section{Kovalenko}

Summary: The article is devoted to the problem of socio-psychological determinants of professional observation of profilers. The essence and content of the concept of observation and its features in the field of profiling are revealed. The profiler's observation ability is considered as a professionally important quality that develops under the influence of socio-psychological factors at the level of the individual, group and society. A set of author's and standardized methods are presented, which made it possible to identify the socio-psychological determinants of profilers ' observation. An empirical model of the socio-psychological determinants of profilers ' observation is described. The results of the study allowed us to identify the structural and content features of observation, which are manifested at the level of the individual, at the level of the group, at the level of mass consciousness. It is shown that the model of observation at the level of personality includes motivationaltarget, cognitive and operational components. The personal, group and social determinants of profilers' observation are revealed.

Keywords: observation, observation, social perception, profiling.
$\mathrm{B}$ настоящее время актуальным становятся научнопрактические исследования в сфере профайлинга. Представляет интерес исследование индивидуально-личностных свойств и качеств профайлеров как субъектов профессиональной деятельности, обуславливающих высокий уровень их профессиональной компетентности, в частности, исследование профессиональной наблюдательности профайлера и лежащих в ее основе социально-психологических детерминант.

В психологической науке профайлинг как технология наблюдения, опроса, оценки и прогнозирования поведения человека на основе показателей вегетативной нервной системы, эмоциональных состояний, вербальных и невербальных проявлений, особенностей внешности и других информативных признаков, является сравнительно новым направлением, появившимся сравнительно недавно и позволяющим получать самую объективную информацию о потенциальной опасности субъекта [5; 8; 10]. Профайлинг, как отмечает А.В. Филатов, является «хорошо структурированной дисциплиной

\author{
Коваленко Максим Александрович \\ Директор, Начиональная гуманитарная академия \\ avestamv@mail.ru
}

Аннотация: Статья посвящена проблеме социально-психологических детерминант профессиональной наблюдательности профайлеров. Раскрыта сущность и содержание понятия наблюдательность и ее особенности в сфере профайлинга. Наблюдательность профайлера рассматривается как профессионально важное качество, которое развивается под влиянием социально-психологических факторов на уровне личности, группы и общества. Представлены комплекс авторских и стандартизированных методик, которые позволили выявить социально-психологические детерминанты наблюдательности профайлеров. Описана эмпирическая модель социальнопсихологических детерминант наблюдательности профайлеров. Результаты исследования позволили выявить структурно-содержательные особенности наблюдательности, которые проявляются на уровне личности, на уровне группы, на уровне массового сознания. Показано, что модель наблюдательности на уровне личности включает мотивационно-целевой, когнитивный и операционный компоненты. Раскрыты личностные, групповые и общественные детерминанты наблюдательности профайлеров.

Ключевые слова: наблюдательность, наблюдение, социальная перцепция, профайлинг.

с собственным инструментарием и технологиями... качество использования которых во многом зависит от двух моментов - наблюдательности и умения делать выводы из собранной информации» [10, с. 9].

В основе понимания сущности психологической наблюдательности как качества личности и психологического наблюдения как процесса лежат теоретические представления отечественной социальной психологии о многофакторной детерминации и взаимосвязанности отношения, образа и процессов социально-психологической интерпретации личности [1]. Психологическое наблюдение является одним из основных психологических навыков в профайлинге, обеспечивающим его успешность, позволяющий считывать невербальные сигналы личности и прогнозировать поведение человека. Взаимосвязь между психическими процессами и свойствами личности отражает взаимосвязь наблюдения как психического процесса и наблюдательности как устойчивого качества личности [7]. 
Психологическая наблюдательность, которая является многокомпонентным психологическим образованием, определяется учеными с различных позиций. Сущностью психологической наблюдательности, согласно Л.А. Регуш, является ее определение как «психического свойства, базирующегося на ощущении и восприятии и являющегося свойством сенсорной организации» $[6$, с. 112]. Рассматривая роль психологической наблюдательности в профессиональной деятельности, большинство ученых определяют ее как комплекс личностных качеств и свойств человека, обеспечивающих способность распознавать и прогнозировать поведение других людей [1; $2 ; 3 ; 4 ; 7]$. Психологическая наблюдательность выступает основой социально-психологической проницательности человека. Ведущей функцией психологической наблюдательности является формирование адекватного и объективного образа наблюдаемого субъекта [8].

С этих позиций в профессиональной деятельности профайлеров наблюдательность понимается как профессионально важное качество, суть которого заключается в фиксации и интерпретации существенных, характерных и малозаметных, но важных для познания и понимания индивидуальных особенностей объектов наблюдения, которые проявляются через внешние признаки. Как отмечают Д.М. Тарасова, Е.А. Петрова «развитая психологическая наблюдательность у специалистов профайлеров позволит избавиться от стереотипных шаблонов и штампов в восприятии и диагностике индивидуально-личностных черт других людей, эффективнее распознавать характерологические и мотивационноценностные черты личности [9, с. 142]. В профессиональной деятельности профайлера психологическая наблюдательность является качеством, обеспечивающим возможности предоставления исчерпывающей информации об объекте наблюдения, которая дает представление о внутреннем мире человека, его чертах характера и привычках, склонностей и способностей, потребностей и интересов, чувств и переживаний, поисков и размышлений, что является основой для выявления и прогнозирования действий и поведения человека.

В связи с этим актуальным представляется описание эмпирической модели социально-психологических детерминант наблюдательности профайлеров как субъектов профессиональной деятельности. Наблюдательность, прежде всего, связана с социальной перцепцией как процессом восприятия (познания) социальных объектов, отдельных лиц, социальных групп и общества в целом [1]. Поэтому наблюдательность профайлера рассматривается нами как профессионально важное качество, развиваемое под влиянием системы социально-психологических факторов - детерминант, которые проявляются на трех уровнях: личности, группы и общества.
Исследование социально-психологических детерминант наблюдательности профайлеров проведено среди профайлеров г. Москвы, общая выборка составила 424 респондента в возрасте от 19 до 53 лет. Для оценки социально-психологических детерминант наблюдательности применялся комплекс авторских и стандартизированных методик, которые позволили выявить социальнопсихологические детерминанты наблюдательности профайлеров. Для изучения личностных детерминант наблюдательности применялись Калифорнийский психологический опросник, опросник структуры темперамента (ОСТ, STQ) В.M. Русалова (1979); для изучения групповых детерминант наблюдательности, отражающих особенности социально-перцептивной сферы межличностной и групповой коммуникации, а также результативность профессиональной деятельности профайлера, применялись: методика «Адекватность интерпретации невербального поведения» (В.А. Лабунская, 1999), тест эмоционального интеллекта EQ Холла (1999); методика «Социальный интеллект» (СИГ) (Дж. Гилфорд, 1960); авторская анкета самооценки результативности профайлера в профессиональной группе (Е.А. Петрова, М.А. Коваленко, Ю.А. Дорофеева 2018); авторская анкета «Психологическая наблюдательность профайлера» (Е.А. Петрова, М.А. Коваленко (2019); экспертная оценки результативности профессиональной деятельности профайлера. (2019г); для изучения детерминант наблюдательности на уровне массового сознания применялся блок методик: метод свободного семантического описания профессии, методика «Личностный дифференциал» (Н.П. Фетискин, В.В. Козлов, Г.М. Мануйлов, 2002), методика «Трехфакторная модель имиджеологического пространства» (Е.А. Петрова, 2001).

Результаты исследования позволили определить модель социально-психологических детерминант наблюдательности профайлеров, которые проявляются на трех уровнях: на уровне личности, на уровне группы и на уровне массового сознания (Рис. 1).

Модель наблюдательности на уровне личности включает мотивационно-целевой, когнитивный и операционный компоненты, каждый из которых выполняет свою роль в ее функционировании. Мотивационно-целевой компонент отражает совокупность мотивов, целей, интересов и установок на познание и понимание индивидуальных особенностей объектов наблюдения, что соответствует представлению о структурно-содержательной сущности наблюдательности, которая характеризуется мотивационно-целевой составляющей. Когнитивный компонент наблюдательности является ее содержательной основой и отражает совокупность особенностей психических процессов - восприятия, внимания, памяти, мышления, которые фиксируют и интерпретируют вербальные и невербальные проявления 


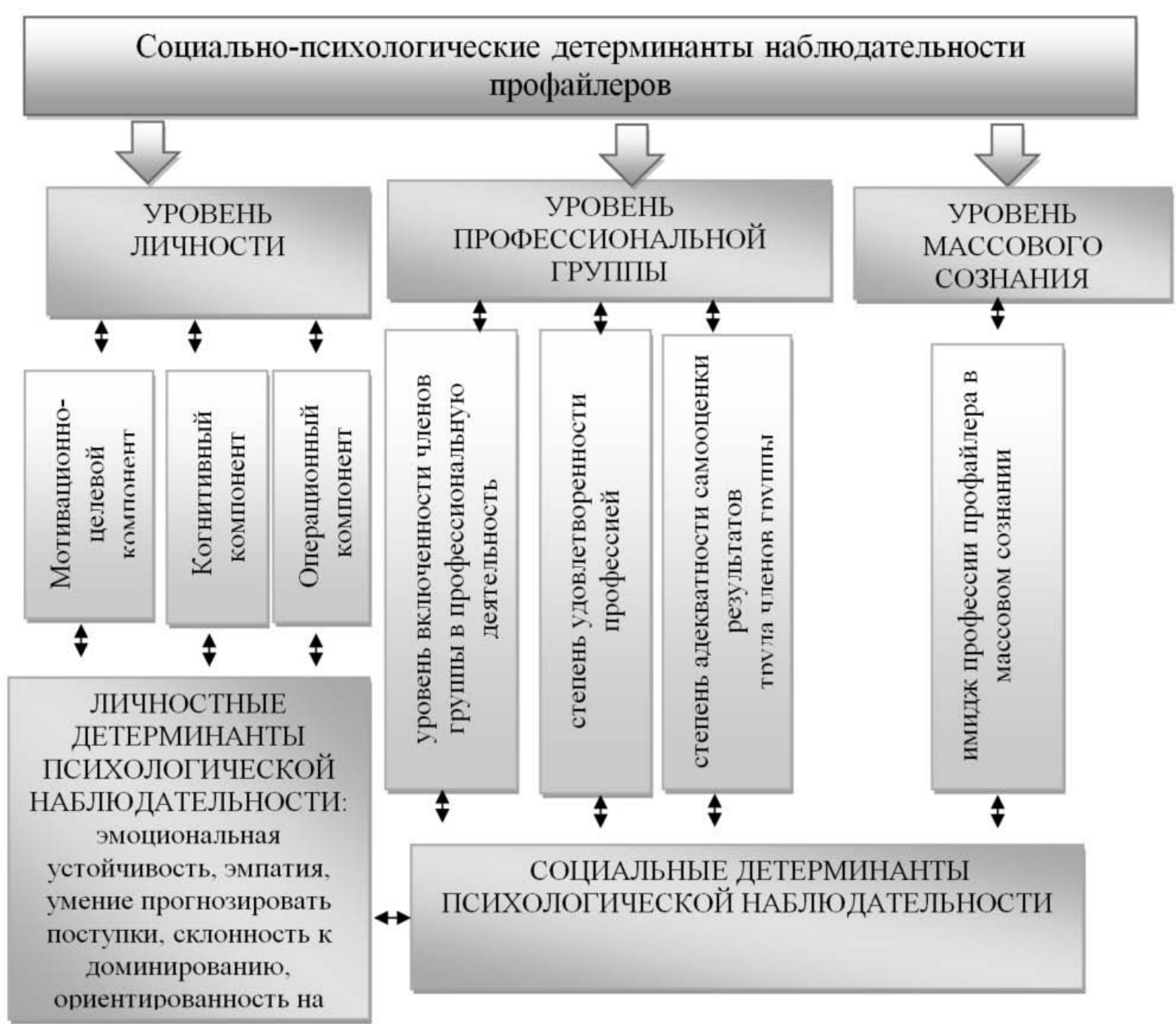

Рис. 1. Модель социально-психологических детерминант наблюдательности профайлеров

индивидуальных особенностей объектов наблюдения. Операционный компонент наблюдательности отражает процессуальный механизм развития наблюдательности в процессе наблюдения как профессиональной деятельности, которая приобретает субъективную значимость под влиянием мотивационно-целевого компонента. В своем единстве эти компоненты - мотивационно-целевой, когнитивный, операционный, составляют основу способности к профессиональной наблюдательности профайлеров. Личностными детерминантами профайлера, согласно полученным результатам, выступают более высокая эмоциональная устойчивость, высокий уровень эмпатии, умение предвосхищать последующие поступки людей на основе анализа реальных ситуаций в общении, склонность к доминированию, при этом, успех работы профайлера не зависит от умения распознавать невербальные проявления в межличностном общении, более наблюдательны и более ориентированы на социально желательные реакции.

На уровне профессиональной группы психологиче- ская наблюдательность детерминирована общим уровнем включенности членов группы в профессиональную деятельность, степенью удовлетворенности профессией, степенью адекватности самооценки результатов труда членов группы. На уровне массового сознания социальными детерминантами наблюдательности профайлеров выступают имидж профессии профайлера в массовом сознании. Однако, согласно полученным результатам, имидж профессии профайлера характеризуется низкой сформированностью, знаковых, образных, когнитивных и эмоциональных компонентов, что оказывает влияние на развитие наблюдательности профайлеров как субъектов профессиональной деятельности.

Полученная в ходе эмпирического исследования модель социально-психологических детерминант наблюдательности профайлеров позволяет определить социально-психологические условия ее развития, а также разработать программы по формированию наблюдательности у специалистов профайлинга. 


\section{ЛИТЕРАТУРА}

1. Бодалев А.А. Психология общения: избранные психологические труды. - М.: Ин-т практ. Психологии; Воронеж: НПО «МОДЭК», 1996. - 256 с.

2. Лабунская В.А. Экспрессия человека: общение и межличностное познание. - Ростов н/Д: Феникс, 1999. - 608 с.

3. Морозова Е.В. Психологическое наблюдение как метод человековедческого познания: дис. ... канд. психолог. наук: 19.00.05. - М., 1995. - 140 с.

4. Петрова Е.А. Визуальная психосемиотика общения. Монография. - М.: Академия имиджелогии, 2015. - 322 с.

5. Профайлинг в деятельности органов внутренних дел: учебное пособие / В.В. Вахнина, Т.В. Мальцева, Т.В. Михайлова, 0.А. Ульянина; Министерство внутренних дел Российской Федерации, Академия управления МВД России. - М.: Академия управления МВД России, 2019. - 98 с.

6. Регуш Л.А. Практикум по наблюдению и наблюдательности. - 2-е изд., переработанное и дополненное. - СПб.: Питер, 2016. - 174 с.

7. Родионова А.А. Личностные детерминанты психологической наблюдательности: дис. ... канд. психол. наук: 19.00.01. - М., 2001. - 173 с.

8. Тарасенко Ю. «Профайлинг: как научится разбираться в людях» [Электронный ресурс] - Режим доступа: http://www.psychologies.ru/selfknowledge/ profayling-kaknauchitsya-razbiratsya-v-lyudyah/.

9. Тарасова Д.М. Теоретическая модель социально-психологической технологии развития психологической наблюдательности у профайлеров / Д.М. Тарасова, Е.А. Петрова // Педагогика и психология в современном мире: теоретические и практические исследования: сборник статей по материалам XXXII Международной научно-практической конференции «Педагогика и психология в современном мире: теоретические и практические исследования». 2020. - № 2(32). - - 137-143

10. Филатов А.В. Психодиагностика. Как разбираться в людях и прогнозировать их поведение. - М.: Издательство АСТ, 2019. - 416 с.

(c) Коваленко Максим Александрович (avestamv@mail.ru). 